\title{
Kajian Kerusakan Lahan Sub DAS Keduang Di Gunung Kendeng Di Desa Ngadipiro, Kecamatan Nguntoronadi, Kabupaten Wonogiri.
}

\author{
Oleh : \\ Joko Winarno \\ Staf Pengajar Program Studi Ilmu Tanah Fakultas Pertanian Unikversitas Sebelas Maret
}

\begin{abstract}
The study site is administratively located at Ngadipiro village, Nguntoronadi subdistrict, Wonogiri regency with the total area of 663.61 ha. The coordinate of the study site lies at latitude of $7^{\circ} 52^{\prime} 00^{\prime \prime}-7^{\circ} 54^{\prime} 15^{\prime \prime} \mathrm{S}$ and longitude of $110^{\circ} 57^{\prime} 45^{\prime \prime}-111^{\circ} 60^{\prime} 45^{\prime \prime} \mathrm{E}$ and the altitude of $196-427 \mathrm{~m}$ a.s.l. According to geomorphologic, the study site is a denudation hilly area, which severely scraped, with the type of primary land use is rainfed, which occupied by annual crops and seasonal crops. This research were aimed at : 1) identify the physical problems and soil cultivation that have caused the land degradation; 2) obtain the alternative solutions for land degradation, which is suitable with the land physical condition. The type of this research is phenomenology description, with the method of surveying. Land mapping technique used the overlay of three maps, i.e : slope map, soil depth map and land use map, which is obtained from the interpretation of topographic map with the scale of 1:25,000. The obtained land unit was used for analysis unit. The land evaluation was carried out based on : 1) observations of land degradation indicators (land cover, outcrop, soil erosion, soil slide, bench erosion and soil depth); 2) soil erosion analysis with USLE formula, which described by soil hazard class. The alternative solution were based on the land degradation types, the threat levels of land degradation and the land management by farmers. Conclusions : Physical problems found are : 1) the climate conditions promoted physical and chemical rocks weathering; 2) The volume of eroded soil corresponded to slope, which shaped "S"; Soil management problem found are : 1) land management by farmers also could drive the land degradation, 2) the low level of farmers economical condition resisted the adoption of technology innovation by farmers economical condition resisted the adoption of technology innovation by farmers. The alternative solution offered are minimum soil tillage (TOT) at 9, 10,11 and 12 land units. On the other hand, the land units of 2, 3, 6, 7, 9, 10 and 12 required the roraks construction and the planting of cover crops and annual crops periodically.
\end{abstract}

Key words : land unit, soil hazard class, soil degradation, land degradation

\section{PENDAHULUAN}

Hujan yang terjadi pada tanggal $26-27$ Desember 2007 di daerah Wonogiri, Solo dan sekitarnya, telah mengakibatkan sungai Bengawan Solo bagian hulu hingga hilir meluap. Yang sangat memprihatinkan yaitu, semua sungai yang berada di atas waduk Serbaguna Gajah Mungkur ini membawa sedimen dalam jumlah yang besar dan berbagai benda yang terbawa oleh aliran air. Menurut Suwartono (Kepala Divisi Air Sumber Air Perum Jasa Tirta Wilayah Bengawan Solo) di Jakarta (Jum'at, 4 Januari 2008) kepada Rizky Andriati Pohan (wartawan Jurnal Nasional http://www.jurnalnasional.com diunduh pada tanggal 26 Februari 2008), cabang-cabang sungai itu menyumbang sedimentasi sekitar 2-3 juta meter kubik per tahun ke dalam waduk.

Keprihatinan Bupati Wonogiri tentang dampak banjir di wilayah hilir sungai Bengawan solo seperti telah diutarakan kepada Widjajadi (Wartawan Media Indonesia) pada hari kamis tanggal 7 Februari 2008;
"Kalau saja pemerintah pusat
bersedia menyetujui usulan
pembangunan 22 cekdam di tiga
aliran sungai wilayah hulu yang
pernah diajukan Pemkab Wonogiri
sejak 2003 silam, saya yakin banjir
akhir Desember lalu tidak perlu
terjadi. Tapi sudahlah, saya kini
mencoba membujuk para bupati yang
ada di wilayah hilir untuk
kepentingan pembangunan waduk di
bagian hulu. Dan syukurlah, Bupati
Karanganyar dan Sragen langsung
menyatakan kesediaan," ungkap
Begug kepada Media Indonesia,
Kamis (7/2).
hathata

http://www.mediaindo.co.idV . diunduh pada tanggal 26 Februari 2008

Sedimen yang masuk Waduk Wonogiri terutama berasal dari sungai-sungai Keduang, Tirtomoyo, Temon, Solo dan Alang. Sistem sungai Keduang merupakan penyumbang sedimen terbesar 
diantara sistem sungai yang lain (Tabel 1). Disamping itu, "outlet" sungai Keduang, berada tepat dibagian atas dari pembangkit listrik, sehingga sedimen yang dibawa sangat mengganggu fungsi generator.

Khususnya kondisi di lokasi penelitian, sejak tahun 1998 mulai terjadi penurunan penutupan lahan yang besar-besaran, menyebabkan terjadinya erosi permukaan dana di bawah permukaan melalui "interface" yang dapat diamati pada bagian tampingan teras. Dampak langsung dari peristiwa tersebut yaitu: terjadinya penurunan jumlah mata air dan penurunan kedalaman tanah dan menurunkan kapasitas tanah dalam menahan air.

Tabel 1. Produksi sedimen tahunan dalam Waduk Wonogiri berdasarkan sumber dan anak sungai

\begin{tabular}{|c|c|c|c|c|c|c|}
\hline \multirow{2}{*}{$\begin{array}{l}\text { Sistem } \\
\text { Sungai }\end{array}$} & \multicolumn{5}{|c|}{ Jumlah dan sumber erosi $\left(\mathrm{m}^{3}\right.$ tahun $\left.{ }^{-1}\right)$} & \multirow[b]{2}{*}{ Total } \\
\hline & Jurang & Longsor & $\begin{array}{l}\text { Tebing } \\
\text { Sungai }\end{array}$ & $\begin{array}{c}\text { Tebing } \\
\text { jalan }\end{array}$ & $\begin{array}{l}\text { Permukaan } \\
\text { tanah }\end{array}$ & \\
\hline Keduang & 67.880 & 2.930 & 9.780 & 3.690 & 1.134 .300 & 1.218 .580 \\
\hline Tirtomoyo & 90 & 11.730 & 19.760 & 2.480 & 469.700 & 503.760 \\
\hline Temon & 30 & 0 & 11.350 & 600 & 61.000 & 72.980 \\
\hline Solo & 220 & 440 & 11.040 & 1.990 & 591.300 & 604.990 \\
\hline Alang & 7.330 & 0 & 66.620 & 730 & 326.600 & 401.280 \\
\hline Lain-lain & 0 & 0 & 11.850 & 1.170 & 363.900 & 376.920 \\
\hline Total & 75.550 & 15.100 & 130.400 & 10.660 & 2.946 .800 & 3.178 .510 \\
\hline
\end{tabular}

Sumber: Tim Studi (2007: S-11)

Tujuan untuk melakukan identifikasi secara mendalam permasalahan fisik dan pengelolaan tanah yang telah mengakibatkan terjadinya kerusakan lahan dan memperoleh alternatif penanganan atau penanggulangan kerusakan tanah yang sesuai dengan kondisi fisik

\section{BAHAN DAN METODE}

Penelitian ini berjenis deskriptif fenomenologi (Moleong, 2004: 15), sedangkan metode penelitiannya yaitu survai (Effendi, 1989: 16). Pemetaan lahan dengan menggunakan tumpang susun peta Peta Kemiringan Lereng, Peta Kedalaman Tanah dan Peta Jenis Penggunaan Lahan yang diperoleh dari hasil interpretasi Peta Rupa Bumi skala 1:25.000. Satuan lahan yang diperoleh dipergunakan untuk satuan analisis. Sampel tanah ditentukan secara purposive (Mantra,dkk., 1989: 169) diperoleh secara komposit pada masing-masing satuan lahan.

Analisis kerusakan tanah dalam penelitian ini dilakukan dengan pendekatan perhitungan erosi dengan rumus USLE yaitu $\mathrm{A}=$ RKLSCP (Wischmeier, 1977; 6-11 dan Arsyad, 1989: 249). Untuk mengetahui sejauh mana erosi yang terjadi akan membahayakan kelestarian produktivitas tanah didasarkan pada Indeks Bahaya erosi (Hardjowigeno,dkk, 1995: 25). Verifikasi data dilakukan dengan metode Tri Angulasi Sumber (Kriyantono, 2006: 70). Alternatif penanganan kerusakan lahan dilakukan dengan pertimbangan: interaksi tanaman dan tanah, permasalahan yang dominan serta kebutuhan, keinginan dan kebiasaan petani setempat.

\section{HASIL DAN PEMBAHASAN}

Daerah penelitian terletak diantara $180-427$ m,dpl yang memiliki rentang suhu udara $22,6{ }^{\circ} \mathrm{C}$ hingga $25,2{ }^{\circ} \mathrm{C}$ (rumus Braak dalam Arsyad, 1989: 223),. Oleh karenanya, secara umum berdasar klasifikasi Koppen (Wisnubroto,dkk., 1983: 70) termasuk dalam tipe iklim A yang dicirikan oleh temperatur udara terdingin lebih besar dari $18{ }^{\circ} \mathrm{C}$. Daerah penelitian termasuk dalam tipe iklim ipe Aw ini dicirikan oleh jumlah bulan-bulan basah tidak dapat mengimbangi kekurangan hujan yang terjadi pada bulan kering.

Berdasar klasifikasi Smith dan Ferguson (Wisnubroto, 1983: 75) daerah penelitian dicirikan dengan jumlah bulan basah $(5,6)$ dan bulan kering $(5,0)$, sehingga termasuk kedalam tipe iklim D (sedang). Adapun berdasar klasifikasi Oldeman daerah penelitian memiliki jumlah bulan basah 2,3 dan bulan kering 6,1 yaitu termasuk dalam tipe iklim E4. Tipe iklim ini tergolong terlalu kering, sehingga untuk tanaman palawija hanya dapat dilakukan satu kali dalam setahun, khususnya pada saat musim hujan.

Berdasar tumpangsusun 3 Peta yang telah disebut, maka daerah penelitian dapat dibedakan menjadi 12 satuan lahan sebagaimana disajikan pada Tabel 1. 
Tabel 1. Satuan Lahan

\begin{tabular}{|c|c|c|c|}
\hline SPL & Simbol & Pemerian & Luas (Ha) \\
\hline 1 & $\frac{S p \cdot 3 / S d .2}{L u .2}$ & $\begin{array}{l}\text { Kemiringan lereng } 15-25 \% \text {, Kedalaman Tanah } 25-50 \\
\mathrm{~cm} \text {, Lahan tegal dominasi jati monokultur }\end{array}$ & 45.12 \\
\hline 2 & $\frac{S p \cdot 3 / S d .3}{L u \cdot 1}$ & $\begin{array}{l}\text { Kemiringan lereng } 15-25 \% \text {, Kedalaman Tanah } 50-90 \\
\mathrm{~cm} \text {, Sawah tadah hujan }\end{array}$ & 147.62 \\
\hline 3 & $\frac{\text { Sp. } 2 / S d .3}{\text { Lu. } 1}$ & $\begin{array}{l}\text { Kemiringan lereng } 8-15 \% \text {, Kedalaman Tanah X }>90 \mathrm{~cm} \text {, } \\
\text { Sawah tadah hujan }\end{array}$ & 151.55 \\
\hline 4 & $\frac{\text { Sp.1/Sd.4 }}{\text { Lu.1 }}$ & $\begin{array}{l}\text { Kemiringan lereng } 0-4 \% \text {, Kedalaman Tanah } x>90 \mathrm{~cm} \text {, } \\
\text { Sawah tadah hujan }\end{array}$ & 72.06 \\
\hline 5 & $\frac{S p .1 / 5 d .4}{\operatorname{Le.} 2}$ & $\begin{array}{l}\text { Kemiringan lereng } 0-4 \% \text {, Kedalaman Tanah }>90 \mathrm{~cm} \text {, } \\
\text { Lahan tegal dominasi jati monokultur }\end{array}$ & 3.87 \\
\hline 6 & $\frac{5 p \cdot 2 / 5 d .3}{\operatorname{te.} 3}$ & $\begin{array}{l}\text { Kemiringan lereng } 8-15 \% \text {, Kedalaman Tanah } 50-90 \mathrm{~cm} \text {, } \\
\text { Lahan tegal (tumpangsari) Komposisi } 30 \% \text { tanaman jati dan } \\
70 \% \text { tanaman polowijo }\end{array}$ & 28.85 \\
\hline 7 & $\frac{5 p \cdot 3 / 5 d .2}{\operatorname{Let} .4}$ & $\begin{array}{l}\text { Kemiringan lereng } 15-25 \% \text {, Kedalaman Tanah } 25-50 \\
\mathrm{~cm} \text {, Lahan tegal (tumpangsari) Komposisi } 70 \% \text { tanaman jati } \\
\text { dan } 30 \% \text { tanaman polowijo }\end{array}$ & 46.67 \\
\hline 8 & $\frac{S p .2 / S d .3}{L u .2}$ & $\begin{array}{l}\text { Kemiringan lereng } 8-15 \% \text {, Kedalaman Tanah } 50-90 \mathrm{~cm} \text {, } \\
\text { Lahan tegal dominasi jati monokultur }\end{array}$ & 7.98 \\
\hline 9 & $\frac{S p .4 / S d .1}{L u .2}$ & $\begin{array}{l}\text { Kemiringan lereng }>25 \% \text {, Kedalaman Tanah } 0-25 \mathrm{~cm} \text {, } \\
\text { Lahan tegal dominasi jati monokultur }\end{array}$ & 94.78 \\
\hline 10 & $\frac{S p \cdot 3 / S d, 2}{L u \cdot 3}$ & $\begin{array}{l}\text { Kemiringan lereng } 15-25 \% \text {, Kedalaman Tanah } 25-50 \\
\mathrm{~cm} \text {, Lahan tegal (tumpangsari) Komposisi } 30 \% \text { tanaman jati } \\
\text { dan } 70 \% \text { tanaman polowijo }\end{array}$ & 12.32 \\
\hline 11 & $\frac{\text { Sp. } 4 / S d .1}{\operatorname{Lu.6}}$ & $\begin{array}{l}\text { Kemiringan lereng }>25 \% \text {, Kedalaman Tanah } 0-25 \mathrm{~cm} \text {, } \\
\text { Lahan tidak diperuntukan }\end{array}$ & 14.74 \\
\hline 12 & $\frac{S p \cdot 4 / S d .2}{L u .4}$ & $\begin{array}{l}\text { Kemiringan lereng }>25 \% \text {, Kedalaman Tanah } 25-50 \mathrm{~cm} \text {, } \\
\text { Lahan tegal (tumpangsari) Komposisi } 70 \% \text { tanaman jati dan } \\
30 \% \text { tanaman polowijo }\end{array}$ & 38.04 \\
\hline
\end{tabular}

Sumber: Kompilasi 3 Peta yang telah disebutkan pada bagian metode penelitian

Pada dasarnya jumlah klasifikasi antara kemiringan lereng dengan kedalaman tanah memiliki kesamaan yaitu 4 kelas. Namun demikian, karena variasinya kondisi jenis penggunaan lahan maka satuan lahan di daerah penelitian dapat dibedakan menjadi 12 kelas.

Dari hasil analisis antara kemiringan lereng dengan kedalaman tanah ternyata memiliki kemiripan dengan Model Hepotitis Hubungan antara proses geomorfologi pada permukaan lahan Thornbury (1966), yaitu seperti kurva huruf "S" (Gambar 1). Pada bagian "interfluve" kejadian erosinya relatif kecil, sebab pada bagian ini jika terdapat air hujan relatif akan terjadi pembagian volume air yaitu sebagian meresap kedalam tanah sebagai air perkolasi dan lainnya berada di permukaan atau sebagai aliran permukaan tanah. Pada bagian lereng dibawahnya merupakan bagian terjunan yang didominasi oleh proses "Fall, Slide" dan pelapukan fisika dan kimia, sedangkan bagian lereng tengah merupakan bagian transportasional yang didominasi oleh "mass movement". Adapun pada lereng kaki didominasi oleh proses pengendapan. 
Namun demikian, ketika dilakukan kompilasi dengan jenis penggunaan lahannya, maka terlihat dengan jelas bahwa tidak ada kesesuaian

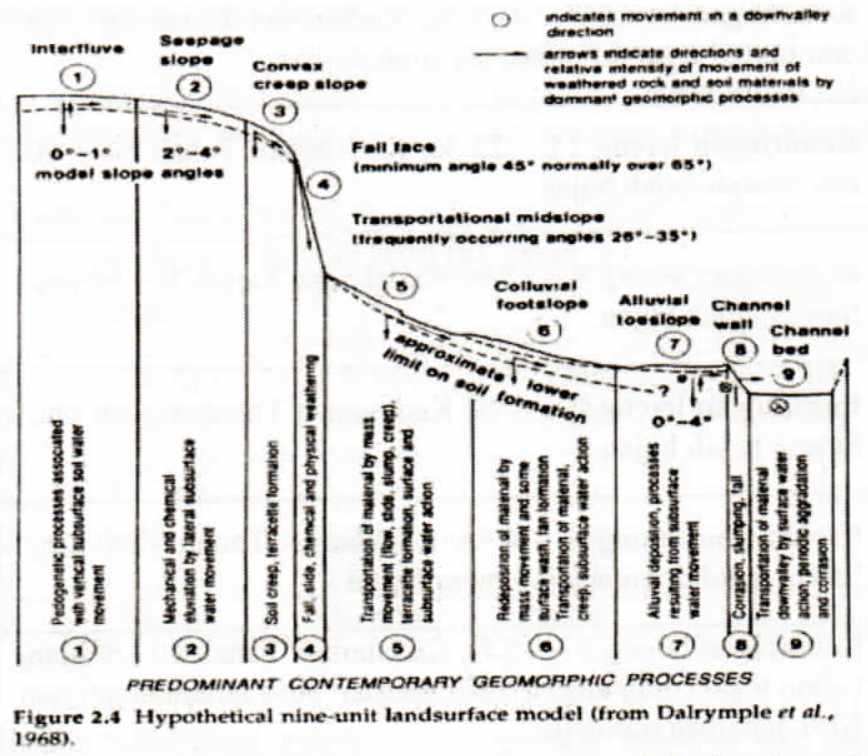

Gambar 1. Model Hepotitis Hubungan antara proses geomorfologi pada permukaan lahan

erosi. Artinya ada faktor lain yang lebih mempengarui besarnya erosi. Dari hasil pengamatan di lapang secara jelas dapat diketahui bahwa pengelolaan lahan dan pengolahan tanah oleh petani sangat mempengaruhi rusak dan tidaknya lahan. Mengingat sempitnya kepemilikan lahan, maka petani setempat berupaya memanfaatkan lahan tersebut secara maksimal. Hal inilah yang mengakibatkan kaidah-kaidah konservasi menjadi diabaikan.

Berdasar hasil wawancara dengan petani setempat, secara jelas diperoleh informasi bahwa petani memiliki pengetahuan tentang konservasi. Namun karena pertimbangan kepemilihan lahan sempit dan biaya perawatan, maka kepentingan konservasi menjadi dinomor duakan. Rogers,dkk (1962: 51) menjelaskan bahwa dalam proses keputusan inovasi sangat dipengaruhi oleh sosial dan budaya mayarakat (individu dan kelompok). Pada kelompok individu / kelompok yang memiliki keterbatasan lahan maupun modal dicirikan oleh tidak beraninya menanggung resiko kegagalan, untuk itu mereka umumnya cenderung melakukan usaha sesuai dengan kebutuhan, keinginan dan kebiasaannya. Implikasi kedepan, untuk menyelamatkan sumberdaya lahan mala pada kelompok masyarakat tersebut perlu ditingkatkan kapasitasnya.

Berdasar analisis indeks bahaya erosi dan tingkat bahaya erosi (Tabel 2), telah semakin jelas bahwa besarnya erosi aktual (USLE) jauh melebihi signifikakan antara kemiringan lereng, kedalaman tanah, jenis penggunaan lahan dan besarnya

erosi yang diperbolehkan. Dengan kata lain bahwa daerah penelitian memang sangat mengkawatirkan jika tidak dilakukan penanganan secara khusus. Sitorus (1985: 45) telah menyebutkan pertanyaan penting yang harus mampu dijawab oleh semua pihak yang bermaksud melakukan evaluasi lahan yaitu bagaimana pengelolaan lahan sekarang dan apa yang akan terjadi jika tindakan pengelolaan lahan sekarang tetap tidak berubah?. Kondisi tersebut akan diperparah jika ditambah dengan tekanan pertambahan penduduk, maka jawabannya adalah akan semakin terjadi penurunan kualitas tanah maupun lahan.

Permasalahan Fisik, adanya batas tegas antar bulan basah dan bulan kering, mengakibatkan proses pelapukan batuan (secara fisik) berjalan lebih intensif. Kenampakan ini sangat jelas terutama pada bagian lereng yang menghadap ke Timur dan ke Barat. Sebagaimana diketahui bahwa aspek lereng ini sangat berpengaruh terhadap tingkat pelapukan batuan. Kondisi pelapukan fisik ini terjadi merata di daerah penelitian

Kejadian erosi di bawah permukaan tanah, disebabkan karena sifat fisik tanah yang kasar, permeabilitas tinggi dan lereng datar, memungkinkan air masuk ke dalam tanah. Air perkolasi ini berhenti pada "interface" dan kemudian mengalir mengikuti arah kelerengan hingga mencapai dasar teras. Air yang berada di atas bahan impermeabel ini keluar melalui celahcelah batuan penguat teras. 
Tabel 2. Tingkat bahaya erosi dan erosi yang diperbolehkan

\begin{tabular}{|c|c|c|c|c|c|c|}
\hline \multirow{2}{*}{$\begin{array}{c}\text { SP } \\
\text { L }\end{array}$} & \multicolumn{2}{|c|}{ Erosi yang diperbolehkan / T } & $\begin{array}{c}\text { Erosi aktual* } \\
\text { (USLE) }\end{array}$ & $\begin{array}{c}\text { Indeks } \\
\text { Bahaya } \\
\text { Erosi }\end{array}$ & $\begin{array}{c}\text { Tingkat } \\
\text { Bahaya Erosi }\end{array}$ & Luas (Ha) \\
\hline 1 & 0,93 & 12,09 & 431,32 & ST & $\begin{array}{c}\text { Sangat Berat } \\
\text { (IV) }\end{array}$ & 45.12 \\
\hline 2 & 1,75 & 22,75 & 129,66 & T & Berat (III) & 147.62 \\
\hline 3 & 2,25 & 29,25 & 79,12 & S & Berat (III) & 151.55 \\
\hline 4 & 2,25 & 29,25 & 31,26 & S & Sedang (II) & 72.06 \\
\hline 5 & 2,25 & 29,25 & 137,44 & T & Berat (III) & 3.87 \\
\hline 6 & 1,75 & 22,75 & 179,90 & T & Berat (III) & 28.85 \\
\hline 7 & 0,93 & 12,09 & 323,36 & ST & $\begin{array}{c}\text { Sangat Berat } \\
\text { (IV) }\end{array}$ & 46.67 \\
\hline 8 & 1,75 & 22,75 & 270,11 & ST & $\begin{array}{c}\text { Sangat Berat } \\
\text { (IV) }\end{array}$ & 7.98 \\
\hline 9 & 0,31 & 4,03 & 2135,90 & ST & $\begin{array}{c}\text { Sangat Berat } \\
\text { (V) }\end{array}$ & 94.78 \\
\hline 10 & 0,93 & 12,09 & 308,46 & ST & $\begin{array}{c}\text { Sangat Berat } \\
\text { (IV) }\end{array}$ & 12.32 \\
\hline 11 & 0,31 & 4,03 & 2421,17 & ST & $\begin{array}{c}\text { Sangat Berat } \\
\text { (V) }\end{array}$ & 14.74 \\
\hline 12 & 0,93 & 12,09 & 1409,65 & ST & $\begin{array}{c}\text { Sangat Berat } \\
\text { (IV) }\end{array}$ & 45.12 \\
\hline
\end{tabular}

Salah satu penanggulangan erosi yaitu penanaman jenis tanaman yang mampu memperbaiki sifat fisik tanah. Idjudin,dkk (2006: 329-331) menyebutkan penerapan teknik konservasi vegetatif dengan satu jalur rumput (raja, setaria, gliriside) dapat memperbaiki sifat fisik tanah dan berbeda nyata dengan kontrol. Peran perakaran rumput (raja dan setaria) dan gliriside yang lebih banyak dan lebih aktif dalam proses

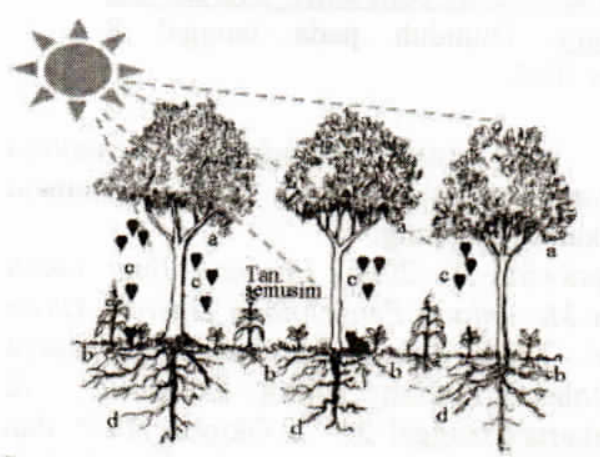

Keterangan:

Gambar. 2. Kombinasi tegakan tanaman pohon dan semusim

a. Tanaman naungan

b. Kompetisi serapan air dan hara antara pohon dan tanaman semusim

c. Daun gugur / seresah

d. Perakaran dalam sifat adaptif (Friday,dkk., 2000: 171).

Sumber: Hairiah,dkk ( ? : 22)

pembentukan mikro dan makro agregat tanah serta memacu aktivitas mikro dan makro organism tanah. Untuk memperkuat bangunan teras bangku, perlu kombinasi penggunaan tanaman tahunan tertentu cukup efektif sebagai penguat teras (Gambar 2). Tanaman kedondong (Spondias purpurea), disamping memiliki nilai ekonomi cukup tinggi, secara agronomi cukup cocok untuk pergunakan sebagai penguat teras, karena memiliki

\section{.}




\section{KESIMPULAN DAN SARAN}

Kesimpulan

1. Permasalahan fisik dan pengelolaan tanah / lahan

a. Permasalahan fisik: 1). Kondisi iklim sangat mendorong terjadinya proses pelapukan fisika dan kimia pada masa batuan, 2). Besarnya erosi yang terjadi bersesuaian dengan kemiringan lerang dan letaknya pada bagian lereng tersebut yang mengikuti Model huruf "S"

b. Pengelolaan tanah / lahan: 1). Pengelolaan tanah dan lahan yang dilakukan oleh petani menjadi faktor penyebab utama terjadinya kerusakan lahan, 2). Keterbatasan ekonomi petani sangat menghambat adopsi inovasi

2. Alternatif penanganan dan penanggulangan kerusakan tanah

a. Pada SPL: 9; 10; 11 dan 12 perlu pengolahan tanah minimal (TOT).

b. Diperlukan pembuatan rorak / saluran buntu (SPL: 2; 3; 6; 7; 9; 10 dan 12).

c. Diperlukan penanaman jenis tanaman penutup tanah dan pohon penguat teras yang sekaligus dapat dimanfaatkan hasil dan kayunya.

\section{Saran}

1. Perawatan teras bangku, guludan dan pembuatan rorak secara bertahap perlu diupayakan terus menerus,

2. Penanaman tanaman dan pohon penutup tanah dan penguat teras (yang sekaligus dapat dimanfaatkan hasil dan kayunya) perlu diupayakan secara bertahap.

\section{DAFTAR PUSTAKA}

Arsyad, S. 1989. Konservasi Tanah dan Air. IPB Press. Bogor.

Effendi, S. 1989. Proses Penelitian Survai. Dalam Singarimbun, M., Sofian Effendi. (Ed). 1989. Metode Penelitian Survai. LP3ES. Jakarta.

Friday, Kathleen S., M.Elmo Driling, Dennis P. Garrity. 2000. Rehabilitasi Padang AalangAlang Menggunakan Agroforestri dan Pemeliharaan Permudaan Alam. International Centre For Research In Agroforestry. Universitas Brawijaya. Fakultas Pertanian. Malang.

Hairiah., K., Didik Suprayogo, Meine Van Noordwijk. ?. Interaksi Antara Pohon-TanahTanaman Semusim: Kunci Keberhasilan Atau Kegagalan Dalam Sistem Agroforestri. Bahan Ajar 2. http://www.worldagroforestry.org/. diunduh pada tanggal 19 September 2008.

Hardjowigeno, S., Soleh Sukmana. 1995. Menentukan Tingkat Bahaya Erosi. Centre For Soil and Agroclimate Research. Bogor.
Idjudin, A.A., T. Notohadiprawiro, M. Dradjad, B.H. Sunarminto. 2006. Dampak Penerapan Teknik Konservasi Tanah Di Lahan Kering Terhadap Sifat Fisik Tanah.AGROSAINS 19 (3), Juli 2006:325-335. ISSN 1411-6170. Berkala Penelitian Pascasarjana Ilmu-Ilmu Pertanian Universitas Gadjah Mada. Yogyakarta

JICA. 2007. Studi Penanganan Sedimentasi Waduk Serbaguna Wonogiri. Laporan Akhir Sementara. Volume II. Nippon Koei and Yachiyo Engineering Co. Ltd.

Kirkby, M.J., R.P.C. Morgan. 1980. Soil Erosion. John Wiley \& Sons. New York.

Kriyantono, R. 2006. Teknik Praktis Riset Komunikasi. KENCANA PRENADA MEDIA GROUP. Jakarta.

Lubis, Darwinsyah., Teguh Prasetyo, Bambang Rahmanto, Elan Masbulan, A. Abdurachman. 1993. Penelitian Pengembangan Usahatani Konservasi Di Daerah Aliran Sungai Bagian Hulu (Proses Perencanaan dan Pelaksanaanya). Departemen Pertanian, Badan Penelitian dan Pengembangan Pertanian, Proyek Penelitian Penyelamatan Hutan Tanah dan Air. Salatiga.

Mangunsukardjo, K. 1985. Interpretasi Citra Untuk Inventarisasi Sumberdaya Lahan. Puspics. UGM-Bakosurtanal. Yogyakarta.

Mantra, I.B., Kasto. 1989. Penentuan Sampel. Dalam Singarimbun, M., Sofian Effendi. (Ed). 1989. Metode Penelitian Survai. LP3ES. Jakarta.

Marwah, S. 2001. Daerah Aliran Sungai (DAS) Sebagai Satu Kesatuan Unit Perencanaan Pembangunan Pertanian Lahan Kering Berkelanjutan. Makalah Ilmiah. Program Pasca Sarjana (S3) IPB. Nopember 2001. Bogor. http://rudyet.250x.com/sem1 012/siti ma rwah.htm. Diunduh pada tanggal 8 Januari 2005

Moleong, L.J. 2004. Metodologi Penelitian Kualitatif. Edisi Revisi. PT. Remaja Rosdakarya. Bandung.

Notohadiprawiro, T. 2006. Peranan Ilmu tanah Dalam Menunjang Pengelolaan Daerah Aliran Sungai. Telah disampaikan pada Lokakarya Pengelolaan Daerah Aliran Sungai di Yogyakarta tanggal 2 - 5 Oktober 1985 dan Direpro oleh Ilmu Tanah Universitas Gadjah Mada tahun 2006 http://soil.faperta.ugm.ac.id/tj/. Diunduh pada tanggal 11 Agustus 2008.

Notohadiprawiro, T. 1999. Diagnosis Fisik, Kimia dan Hayati Kerusakan Lahan. Makalah Ilmiah. 
Telah dipresentasikan pada Seminar Penyusunan Kriteria Kerusakan Tanah / Lahan. Di Bapedal. Yogyakarta pada Tanggal 1-3 Juli 1999. Yogyakarta.

Notohadiprawiro, T. 1996. Lahan Kritis dan Bincangan Pelestarian Hidup. Makalah Ilmiah Telah disampaikan pada Seminar Nasional Penanganan Lahan Kritis Di Indonesia pada Tanggal 7-8 Nopember 1996. Di INAGRO (PT. Intidaya Agrolestari. Parung. Bogor. http://soil.faperta.ugm.ac.id/tj/.pdf Diunduh pada tanggal 17 Juli 2008

Pringadi, BH. 2004. Pengendalian Kerusakan Lahan Hutan dan Air. INFOMATEK Vol 6 Nomor 1 Maret 2004. http:www.unpas.ac.id/ Download tanggall Maret 2008.

Rizky Andriati Pohan. 2008. DAS Butuh Dukungan Tanaman Keras. Jurnal Nasional, 4 januari 2008. http://www.jurnalnasional.com/. diunduh pada tanggal 26 Februari 2008

Rogers, E.M., F. Floyd Shoemaker. 1962. Communication of Innovations. A Cross-
Cultural Approach. Edisi ke 2. The Free Press. New York.

Suharyadi. 2003. Efektivitas Vegetatif Dalam Konservasi Tanah Dan Air Pada Suatu DAS. Makalah Ilmiah. Program Pasca Sarjana / S3 Institut Pertanian Bogor.

Thornbury, W.D. 1966. Principle of Geomorphology. Wiley. New York.

Widjajadi. 2008 . Bupati Wonogiri Ajak Bupati Wilayah Hilir Bantu Bangun Cekdam. Media Indonesia, Jum'at 4 Januari 2008. http://www.media-indonesia.com/. diunduh pada tanggal 26 Februari 2008.

Wischmeier, W.H (ED). 1977. Soil Erosion: Prediction and Control. $R K L S C P$. Soil Conservation Society of America. Library of Conggres Catalog Card Number: 77:74183. IOWA.

Wisnubroto, S., Siti Lela Aminah. S, Mulyono Nitisapto. 1983. Asas-Asas Meteorologi Pertanian. GHALIA INDONESIA. Jakarta. 